\title{
RESTORATION OF KNEE JOINT FUNCTION IN CHRONIC RHEUMATOID ARTHRITIS*
}

\author{
BY \\ ROBERT L. PRESTON \\ From the Department of Orthopaedic Surgery, Post-graduate Medical School, New' York University, N.Y.
}

(RECEIVED FOR PUBLICATION AUGUST 24, 1953)

The restoration of function to the severely deformed knee has always presented one of the most difficult problems to be encountered in the management of patients with chronic rheumatoid arthritis. In the past, the chances of satisfactory functional rehabilitation were so questionable that it became customary to fuse these joints rather than to attempt to restore motion. However, now that cortisone and ACTH are available for use before and after operation, the outlook is more favourable. Irrespective of the place which these hormones finally assume in the therapy for the control of rheumatoid arthritis, there is no question but that they have supplied the surgeon with an important tool. Clinical studies indicate that it is now feasible to perform an operation on these knees extensive enough to correct all the principal pathological features. There is reasonable assurance that the rheumatoid inflammation will be controlled, post-operative scar formation and oedema inhibited, and post-operative pain minimized. The feeling of well-being which frequently results from the use of cortisone or ACTH makes it easier for the patient to co-operate in the postoperative programme which is necessary to complete the functional rehabilitation.

\section{Pathology}

This paper is restricted to the consideration of the severely disabled, painful knee with marked permanent deformity and severe limitation of motion. The deformed posture of the knee is fixed by firm contracture of the structures on the flexor side of the joint: the capsule, muscles, fasciae, nerves, vessels, and skin. The structures on the extensor side of the joint are permanently elongated. The marked overstretching of the extensor motor apparatus, which occurs in so many cases, often constitutes a more serious handicap to the restoration of active control than the severe muscular atrophy. Strong peri-

* Read at the Annual Meeting of the American Rheumatism Association, May 28, 1953. articular adhesions bind together the structure which must be made to move.

Within the joint there is also extensive adhesion $\vec{N}$ The suprapatellar pouch may be entirely obliterated $+\stackrel{+}{+}$ The patella is usually restricted in motion and irio many cases it is completely immobilized as the resul $b$ of firm adhesions which fix it to the articular surface? of the femur. Pannus completely covering the articular surfaces is unusual, but in most instances there is some encroachment of fibrous tissue on to@ the periphery of the articular surfaces. Articularo cartilage is missing beneath the pannus or in areas in which scar tissue is attached to the articu\& $\overrightarrow{0}$ surface. The articular cartilage which is preser cew is usually thin and fibrillated, but it is rare for bone to be exposed. The menisci are marke degenerated or are missing. In some portions of the joint the synovial membrane may be essentiallyo normal in appearance. In other areas the synoviao may be considerably thickened and may have the injected appearance of subacute inflammation. It is: unusual for the entire synovia to be inflamed.

If severe disability has been present for some years there may be extensive hypertrophic spur formation at the periphery of the articular surfaces. The peri $\frac{0}{2}$ articular bone is usually very porous and in manyo instances it is so soft that it is possible to push a3. blunt instrument such as a haemostat through the cortex of the femur. The articular surfaces of the femur or the tibia are often irregular in contour dueo to lysis or crushing of the subarticular bone.

\section{Operative Technique}

If these joints are to function satisfactorily after operation, the contracted tissues must be lengthened 0 so that the knee can be brought into the position of full extension, the physiological tension of the extensor motor apparatus must be restored so thate the joint can be moved skilfully into functionalo position by active muscular power, and the intra-? articular causes of impaired active and passive $\mathbb{Z}$ 
motion in the anterior compartment must be eliminated.

For the correction of flexion deformity the posterior capsulotomy operation, reported by Wilson (1929), produces a more satisfactory result than the mere lengthening of the hamstring tendons. In this procedure the biceps femoris tendon and the fascia lata are lengthened and the posterior capsule of the knee joint is stripped from the bone.

To prevent post-operative lateral instability (Preston, 1941), I have modified the technique by stripping the periosteum from the posterior surface of the femur and entering the posterior compartment of the joint from above; only the posterior attachment of the capsule is stripped, so as to avoid injury to the medial and lateral collateral ligaments.

After normal passive extension has been restored, the anterior compartment of the joint is entered to free the structures which glide during movement of the joint. If the suprapatellar pouch, or the joint cavity lateral, medial, and distal to the patella are obliterated, the adhesions are cut and the intraarticular space is re-established. To ensure adequate room in the anterior compartment of the knee, most of the fat pad is usually excised. The irregularities on the articular surfaces and the osteophytes on the patella, femur, and tibia are removed to avoid irritation of the soft tissues which must move over the bones on motion of the knee. In some instances a considerable portion of the articular aspect of the patella is excised, as well as any diseased portions of the synovial membrane.

If the patellar tendon and the quadriceps muscle have become too lax, they are tightened by moving the tubercle of the tibia distally a distance of oneeighth of an inch for every $10^{\circ}$ of flexion deformity (Preston, 1940).

After the operation, it is essential to keep the patient under close observation until strong active extension has been restored to the knee and all tendency to flexion contracture has disappeared.

\section{End-Results}

Follow-up data are available on eighteen knees of eleven patients upon whom the comprehensive reconstruction operation was done while the patient was under the influence of cortisone or ACTH. The irreversible pathological changes in all these knees were severe, and all the patients were totally disabled before operation. Five of the patients had not been able to walk for some time and the remainder were using crutches. They have since been observed for periods of 6 to 24 months.

Arthrotomy of the anterior compartment of the knee was required in all cases.
Posterior capsulotomy was performed in thirteen knees, but was not required for the correction of the deformity in five knees of three patients.

The flexion deformity of these five knees was slight, varying from 20 to $30^{\circ}$, and when manipulation was attempted before making the incision for the posterior capsulotomy, it was discovered that the deformity could be corrected completely with the use of only mild force.

It was necessary to displace the tubercle of the tibia in seven knees of four patients. In one of these the tubercle was displaced at a later operation when it was discovered that the quadriceps could not be shortened sufficiently to lock the knee in full extension. With one exception, the knees which required the displacement of the tubercle were severely deformed, 50 to $80^{\circ}$ of fixed flexion being present.

In evaluating the end-results, a satisfactory result has been regarded as one in which the patient is able:

(1) to do sufficient walking to engage in ordinary activities, with the knee in functional position, without pain;

(2) to flex the knee sufficiently to climb stairs or to get up from a chair.

Some of the patients in the successfully rehabilitated group use a cane for extensive walking, but none of them uses crutches. Five of the patients in this group have had persistent, mild to moderate rheumatoid activity throughout the entire period of observation. Nine of the patients ( 82 per cent.) had a satisfactory end-result.

The pathological changes in and around the knees of two patients with unsatisfactory end-results were no more severe than in some of those successfully rehabilitated.

One has maintained a satisfactory range of active motion, but the knees have been too painful for more than very limited walking. As she had not been able to walk at all before operation, this result represents an improvement, and the poor end-result seems to be due entirely to our inability to control the systemic rheumatoid arthritis.

The other patient has pain only on extensive walking, but she has practically no motion and there has been a 30 per cent. recurrence of flexion deformity in one of her knees. The systemic rheumatoid arthritis has remained moderately active throughout the entire period of observation, but this has not seemed to be a significant factor in the end-result. The most important cause of the failure to rehabilitate this patient was a marked psychological instability which made it impossible to secure any co-operation in the necessary post-operative muscular rehabilitation programme. As she was unable 
to walk before the operation, even this poor result represents some improvement in her situation.

\section{Case Reports}

The important features of three representative cases are given below.

Case 1, Female, aged 50 years, had rheumatoid arthritis with generalized joint disability for 13 years and the disease was moderately active continuously during this entire period. When she was first seen, the range of passive motion of the left knee was from $165^{\circ}-120^{\circ}$ (Fig. 1), and the range of passive motion of the right knee was from $165^{\circ}-110^{\circ}$ (Fig. 2). $X$ rays revealed narrowing

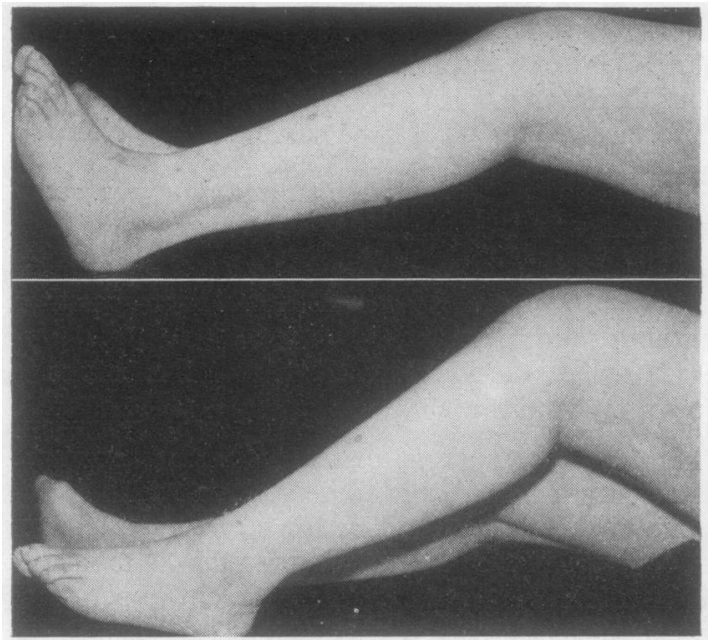

Fig. 1.-Case 1, range of passive motion of left knee before manipulation.

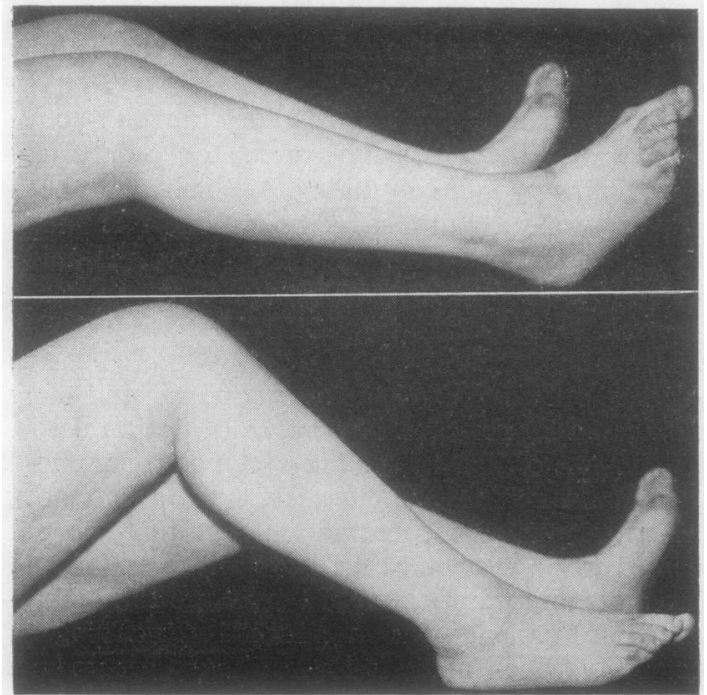

Fig. 2.-Case 1, range of passive motion of right knee before manipulation. of the intra-articular space, sclerosis of the subarticular $\stackrel{\mathbb{D}}{\mathscr{D}}$ bone, and osteophyte formation (Fig. 3). In the rehabili- $\overline{3}$ tation of knee joints in which the irreversible patho- $\square$ logical changes are severe, complete extension must be

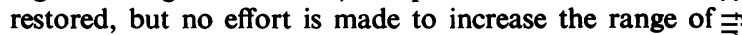
flexion beyond $90^{\circ}$. In this case, the limitation of flexion $\stackrel{5}{+}$ of both knees was severe, but, as there was only mildo limitation of extension, open operation was not indicated. $\frac{\bar{\sigma}}{}$

Both knees were stretched into full passive extension $\overline{\overline{\bar{\rho}}}$ under general anaesthesia. Within 2 months the patient $\underset{\nabla}{\varnothing}$ developed the ability to bear weight with both knees at the full limit of extension. Flexion of the right knee was $ळ$ possible to $100^{\circ}$ and of the left to $90^{\circ}$. At that time there $\overrightarrow{0}$ was no more than mild soreness in the knees on prolonged walking.

During the next year the same range of active motion was maintained, but as activity was increased there was a gradual increase of pain in the right knee. The markedly rough crepitation which developed in this knee seemed $\vec{N}$ to be the principal cause of pain, there was no significant pain or soreness in any other joint.
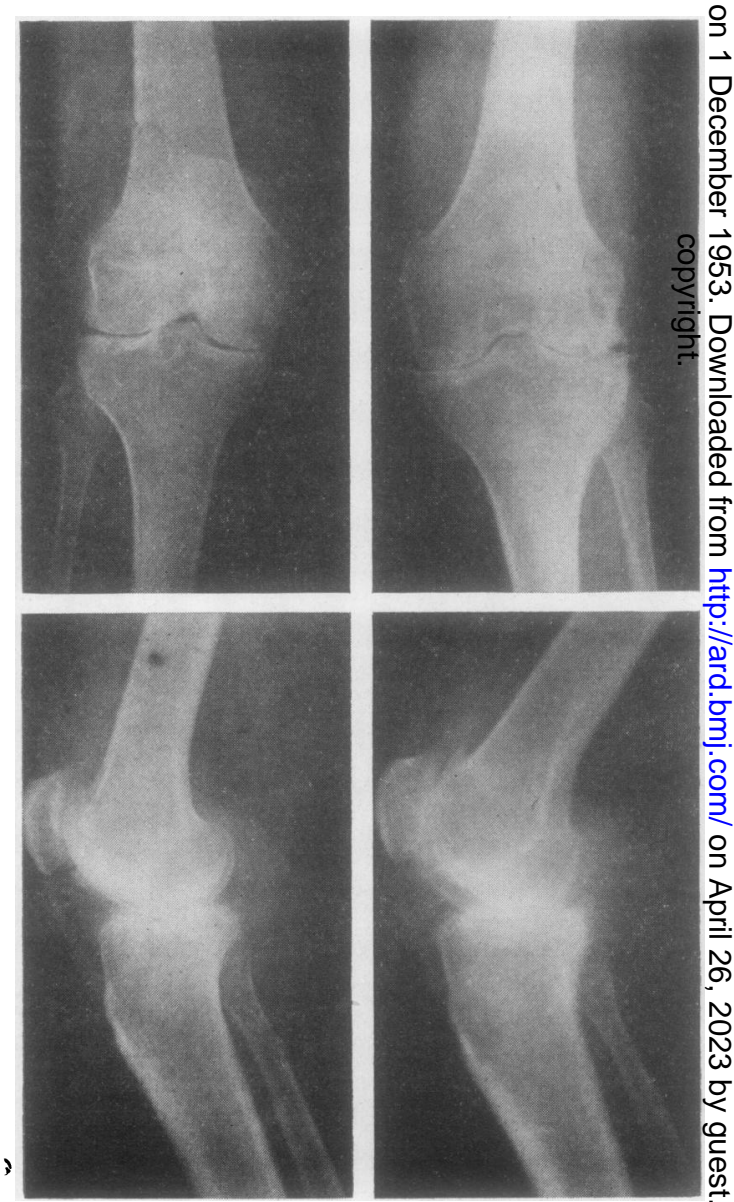

Fig. 3.-Case 1, $x$ rays of knee before ma nipulation. 


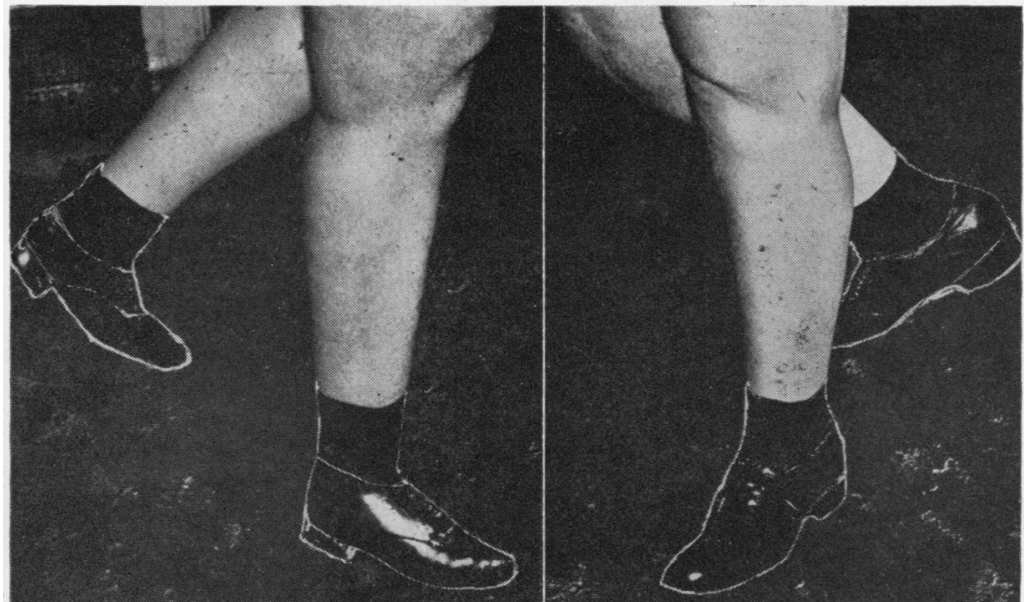

Fig. 4.-Case 1, standing with whole weight supported on one foot, 9 months after operation on right knee.

One year after the manipulations, the anterior compartment of the right knee was explored. The intracapsular space was re-established, the scarred and inflamed portions of the synovia were excised, and the marked bony irregularities on the articular surfaces of the patella and the femur were removed. It was possible to restore reasonably normal contours to the joint surfaces. The knee was immobilized in a cast for one week after this operation, and after 2 months of corrective exercise, the range of active motion of this knee was from $180^{\circ}$ $100^{\circ}$ without crepitation and with only mild soreness. Fig. 4 shows the patient bearing weight on one foot with the knee locked in extension by active muscular power, 9 months after operation.

At the last examination, 18 months after operation, the range of active motion in the right knee was from $180^{\circ}$ $100^{\circ}$ and in the left from $180^{\circ}-85^{\circ}$. Only minimal crepita-
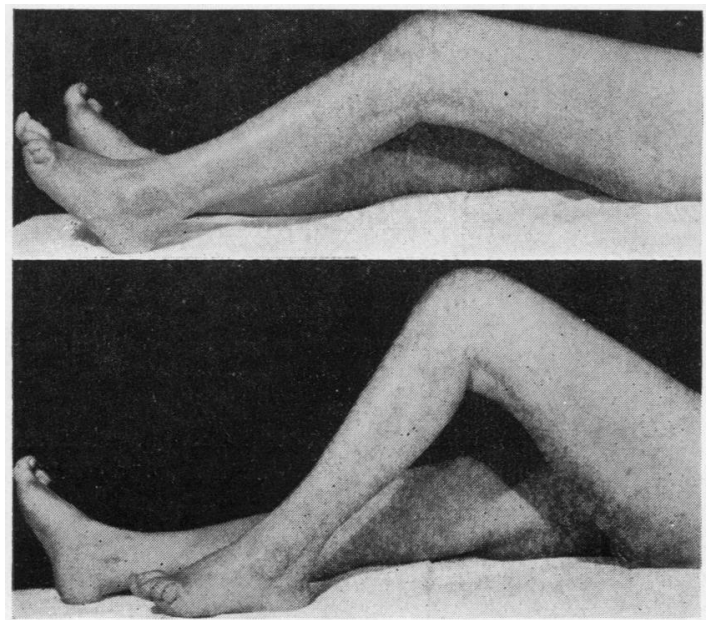

Fig. 5.-Case 2, pre-operative range of passive motion of left knee. tion was present in the right knee. At that time only slight soreness developed in the knees on prolonged walking. The rheumatoid arthritis remained moderately active throughout the entire period of observation.

Case 2, Housewife, aged 47 years, had rheumatoid arthritis with generalized joint involvement for 13 years before the operation on her left knee. At the time of the operation and during the 2 years of observation after operation, the rheumatoid arthritis was only mildly active. The pre-operative range of passive motion of the left knee was from $140^{\circ}-90^{\circ}$ (Fig. 5).

The operation consisted of posterior capsulotomy, anterior arthrotomy, and transplant of the tubercle of the tibia. After operation the knee was immobilized in a cast for one week, and for the next 3 weeks traction was used when the patient was in bed. Corrective exercises for the quadriceps muscle were started when the cast was removed and these exercises were continued several times a day for 5 months.

Fig. 6 shows the patient bearing all her weight on the left leg 2 years after operation; the range of active motion was from $180^{\circ}-100^{\circ}$, and there was no pain or soreness even on extensive use of the knee.

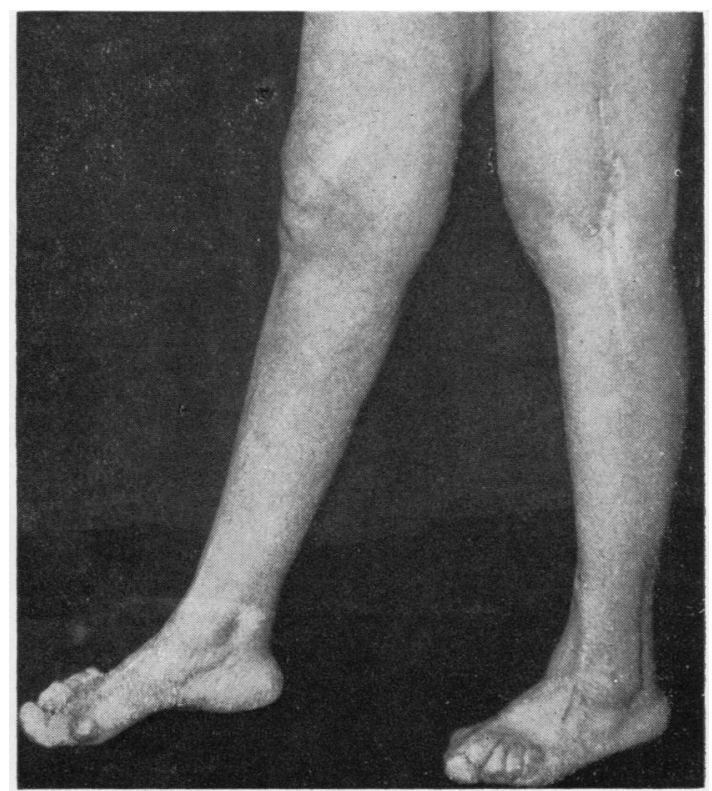

Fig. 6.-Case 2, standing with whole weight on left leg, 2 years after operation. 
Case 3, Housewife, aged 50 years, had rheumatoid arthritis with generalized joint involvement for 10 years before operation. For nearly 10 years she has been confined to bed or to a wheel chair because of severe deformities of the knees. The rheumatoid arthritis was moderately active from the onset up to the time of operation. The pre-operative range of passive motion of the left knee was from $100^{\circ}-30^{\circ}$. The range of active extension was a few degrees less than the range of passive extension (Fig. 7).
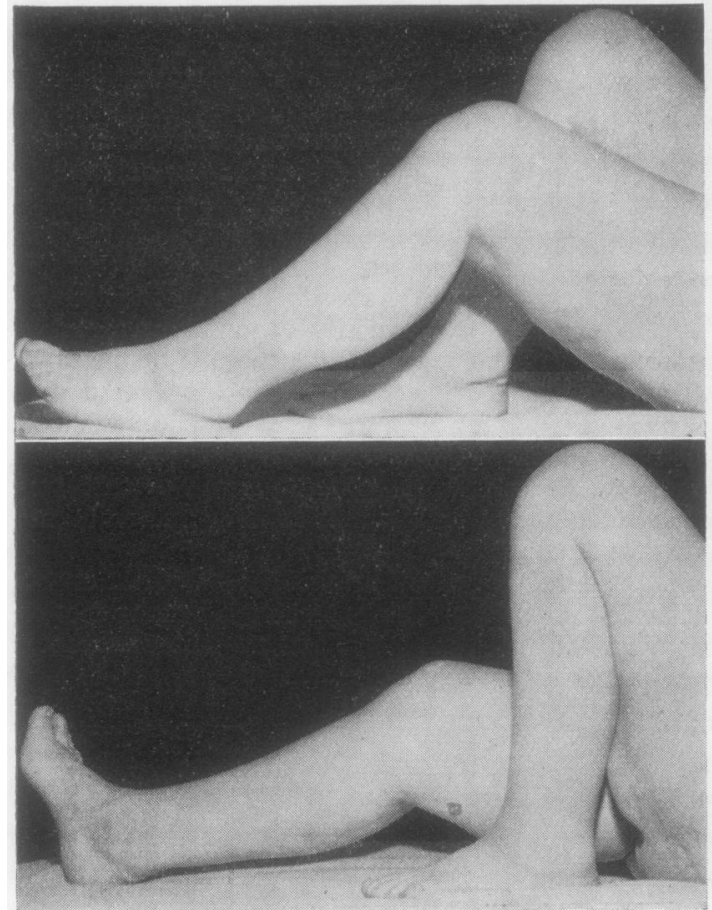

Fig. 7.-Case 3, range of passive flexion and extension of left knee before operation.

She complained of generalized pain of considerable severity at the extremes of motion. Pre-operative $x$ rays revealed marked destructive changes in the left knee and only slight bony changes in the right knee (Fig. 8).

Posterior capsulotomy, anterior arthrotomy, and transplant of the tubercle of the tibia were required to restore function to the left knee.

In the right knee there was some chronic rheumatoid pathology, but the principal cause of the flexion deformity was the long-continued fixation of this joint in flexed position which was necessitated by the severe fixed deformity of the opposite knee. The range of passive motion of the right knee was from $160^{\circ}-40^{\circ}$ (Fig. 9). The right knee has not been included in this end-result study as open operation was not required and the deformity was corrected easily by stretching under anaesthesia.
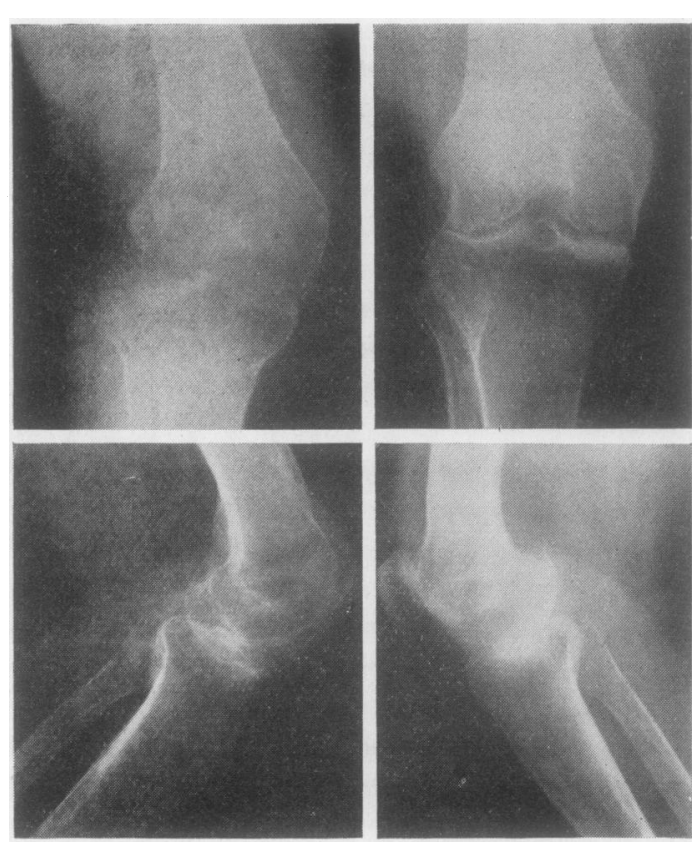

Fig. 8.-Case 3 , pre-operative $x$ rays.

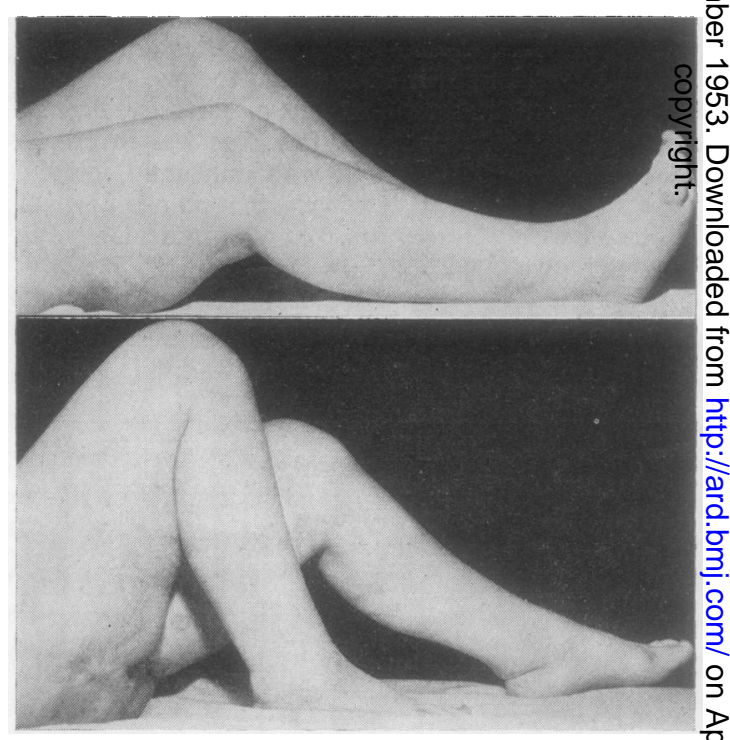

Fig. 9.- Case 3, range of passive flexion and extension of right knee 을. before manipulation.

Casts were applied to both knees for one week after $N$ the correction of the deformities. After the removal of the casts, the knees were held in full extension by means $\sigma$ of traction until the patient left the hospital. Corrective exercises for the muscles of the hips and legs were per- $\stackrel{0}{C}$ formed several times a day.

Fig. 10 (opposite) shows the patient standing on one? 


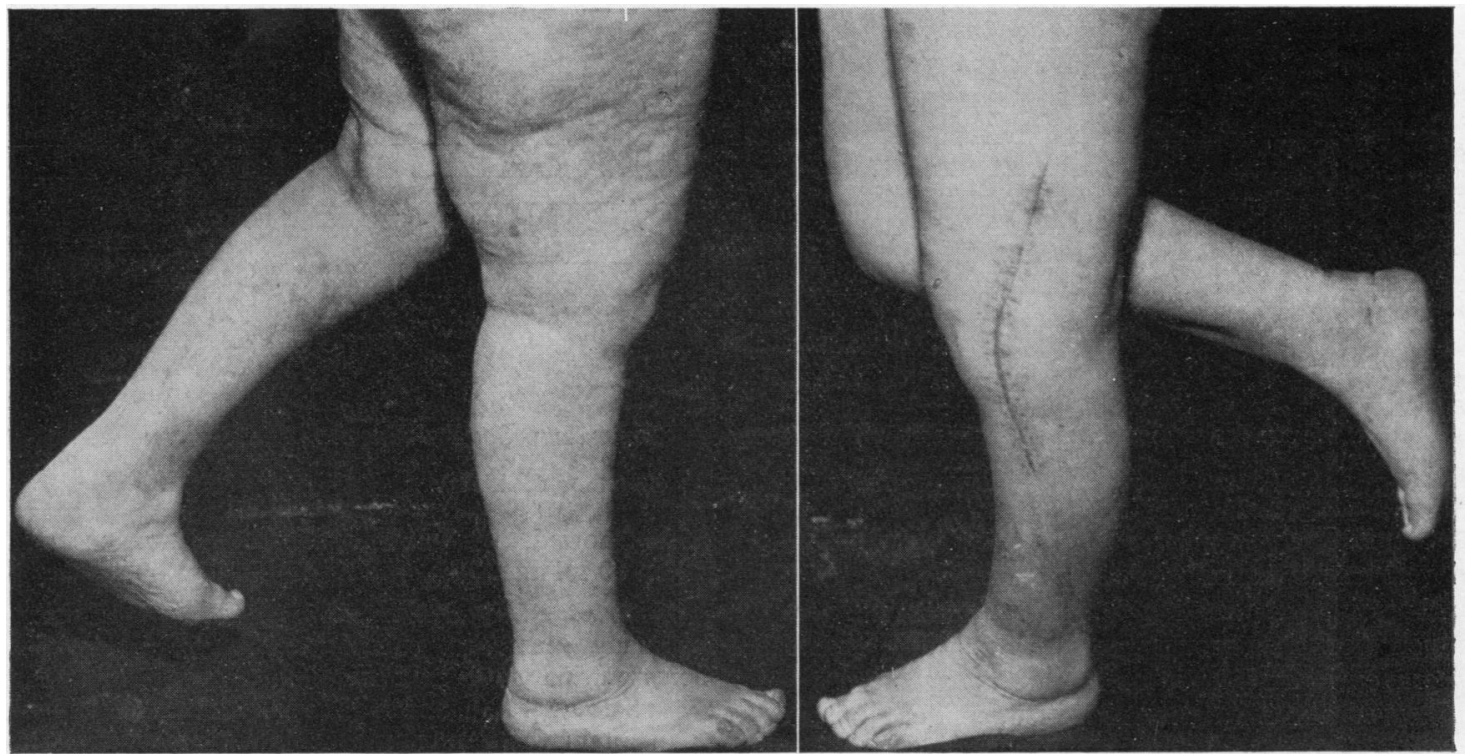

Fig. 10.-Case 3, standing with whole weight supported on one foot with knee locked in functional position, 2 months after operation.

foot with the knee in functional position at the time of leaving the hospital, 2 months after operation.

At the time of the last examination, 6 months after operation, both knees could be locked in functional position by active muscular power. The range of flexion was the same as before operation. There was no synovial effusion in either knee. Mild soreness was still present on extensive use and the muscular strength was still deficient. A cane was used for extensive walking. It was recommended that the corrective exercises be continued and it is expected that muscular endurance will eventually improve so that the cane may be discarded.

\section{Summary}

(1) The indications and appropriate operative technique for the reconstruction and rehabilitation of painful knees disabled by arthritis are discussed.

(2) The results of surgical treatment in eighteen knees of eleven patients are described, and three cases are illustrated in detail.

(3) It is concluded that when cortisone or ACTH are used before and after the surgical reconstruction of severely deformed rheumatoid knees, it is feasible to do an operation extensive enough to correct all the principal pathological features.

(4) A satisfactory end-result is dependent upon adequate surgery, control of rheumatoid inflammation, and co-operation of the patient in postoperative rehabilitation programme.

\section{REFERENCES}

Preston, R. L. (1940). Amer. J. Surg., 50, 303. -, and Hartung, E. F. (1941). Surg. Clin. N. Amer., 21, 593. Wilson, P. D. (1929). J. Bone Jt Surg., 11, 40.
Rétablissement de la fonction articulaire du genou dans l'arthrite rhumatismale chronique

\section{RÉSUMÉ}

(1) On discute les indications et les procédés opératoires appropriés dans la reconstruction et la rehabilitation des genoux douloureux invalidés par l'arthrite.

(2) On décrit et on illustre les résultats du traitement chirurgical de dix-huit genoux chez onze malades.

(3) On conclut que l'emploi de la cortisone et de l'ACTH avant et après la reconstruction chirurgicale des genoux rhumatismaux sévèrement déformés permet de procéder à des opérations d'envergure suffisante pour corriger tous les principaux traits pathologiques.

(4) Le résultat définitif satisfaisant dépend de la chirurgie appropriée, du contrôle de l'inflammation rhumatismale et de la coopération du malade dans les mesures de rehabilitation postopératoire.

Restablecimiento de la función articular de la rodilla en la artritis reumatoide crónica

\section{Sumario}

(1) Se discute las indicaciones y los procedimientos operatorios apropiados en la reconstrucción y la rehabilitación de rodillas dolorosas incapacitadas por la artritis.

(2) Se describe, con ilustraciones, los resultados del tratamiento quirúrgico de dieciocho rodillas en once enfermos.

(3) Se concluye que el empleo de cortisona y de ACTH antes $y$ después de la reconstrucción quirúrgica de rodillas reumáticas severamente deformadas permite operaciones de envergadura suficiente para corregir todos los defectos principales.

(4) El resultado final satisfactorio depende de la cirugía apropiada, del control de la inflamación reumática $y$ de la cooperación del enfermo en las medidas de rehabilitación postoperatoria. 